\title{
Quality of life before and after coronary artery bypass grafting: findings among pre-operative and post-operative patients at the National Hospital of Sri Lanka
}

\author{
Atapattu P M ${ }^{1}$, Warnasooriya W M A D ${ }^{2}$ \\ Journal of the Ceylon College of Physicians, 2016, 47, 92-97 \\ DOI: http://doi.org/10.4038/jccp.v47i2.7790
}

\begin{abstract}
Background: Cardiovascular disease is a main cause of morbidity and mortality worldwide. Coronary artery bypass grafting (CABG) is a common method of treatment for patients with coronary artery disease, which is known to improve quality of life (QoL). However little is known about how CABG affects QoL in the Sri Lankan setting.
\end{abstract}

Objective: The purpose of this study therefore was to document the pre-operative and post-operative QoL of the patients undergoing CABG at the National Hospital of Sri Lanka (NHSL).

Methods: This descriptive cross sectional study was conducted from January-March 2013 in the thoracic unit and cardiology unit of NHSL on two groups of patients matched for age, gender and body mass index: pre-operative patients awaiting CABG (preCABG) and post-operative patients who had undergone CABG (post-CABG); with 50 subjects in each group. The health and functioning, socioeconomic, psychological/spiritual and family subscales of QoL were assessed using Ferrans and Powers Quality of Life Index - Cardiac IV Version.

Results: The post-CABG group had higher mean scores for overall QoL and health and functioning, psychological/spiritual and family subscales and lower mean scored for social and economic subscale than the pre-CABG group, regardless of age and gender. In the post-CABG group, older patients had significantly higher scores for health and functioning subscale than younger patients $(p<0.05)$.

Conclusion: QoL was better in most aspects in the post-CABG group than the pre-CABG group, especially among the older patients.

\footnotetext{
${ }^{1}$ Department of Physiology,

Faculty of Medicine, University of Colombo, Sri Lanka.

${ }^{2}$ Allied Health Sciences Unit,

Faculty of Medicine, University of Colombo, Sri Lanka.

Corresponding author: PMA

E-mail: piyushaatapattu@yahoo.com
}

Key words: coronary artery bypass grafting, quality of life, pre-operative and post-operative

\section{Introduction}

By the end of the 20th century, cardiovascular diseases (CVD) had become the major cause of death globally. ${ }^{1}$ An estimated 17.3 million people died from CVD in 2008, representing $30 \%$ of all global deaths ${ }^{2}$ and 7.3 million deaths were due to coronary heart disease (CHD). ${ }^{3}$ Over $80 \%$ of CVD deaths take place in low and middle-income countries and occur in almost equal numbers in men and women. ${ }^{2}$

In 2003 CVD was ranked within the first few leading cause of hospital deaths in Sri Lanka, ${ }^{4}$ with 524 deaths per 100000 population, higher than that observed in many high income countries. ${ }^{5} \mathrm{CHD}$ is the leading cause of death in Sri Lanka and has accounted for 34\% of deaths in an autopsy study. ${ }^{6}$ In comparison, CHD accounts for only $17 \%$ of deaths in the United States. ${ }^{7}$

Coronary artery bypass grafting (CABG) is commonly used to treat CVD worldwide. ${ }^{8}$ Data obtained from The Society of Thoracic Surgeons revealed that the number of patients undergoing CABG was gradually increasing. ${ }^{9}$ In 2008, 408000 in-patient bypass procedures were performed in the United States. ${ }^{7}$ In Sri Lanka, 1480 cardiothoracic surgeries have been performed in the National Hospital of Sri Lanka (NHSL) in 2007, most of them being CABG. ${ }^{10}$

Traditionally, outcomes such as mortality or morbidity have been used to assess therapeutic interventions. ${ }^{11}$ Along with the substantial decline in operative mortality with CABG over the past 30 years, quality of life (QoL) has also become an important outcome to more clearly define the benefits and risks associated with cardiac surgeries and assist patients to make better informed treatment decisions. ${ }^{12}$

The ACC/AHA guidelines for CABG suggest that an improvement in QoL is the primary indication for the operation. ${ }^{13}$ Thus, in addition to survival, QoL has become an important outcome of bypass surgery. Hence, there is growing interest in using QoL outcomes as a tool to 
evaluate the benefits risks ratio associated with CABG to help clinicians to make decisions towards the surgery.

Currently CABG has become one of the major open heart surgeries, performed annually both in governmental and non-governmental sectors of Sri Lanka. Though there are a significant number of CABG surgeries performed in Sri Lanka, there is a dearth of published data on the QoL of patients before and after CABG in the local context. The purpose of this study therefore was to document the pre-operative and post-operative QoL of the patients undergoing CABG at the NHSL, which may aid clinical reasoning and post-CABG rehabilitation.

\section{Methodology}

This descriptive cross sectional study was conducted over 3 months (January-March 2013) in the thoracic unit and cardiology unit of NHSL on two groups of patients: pre-operative patients awaiting CABG (pre$C A B G$ ) and post-operative patients who had undergone CABG (post-CABG); with 50 subjects in each group. The pre-CABG group, was selected from patients awaiting their first CABG in the thoracic unit, 1-7 days prior to surgery. The post-CABG group was selected from patients who had undergone CABG 10-15 months before, managed post-operatively in the rehabilitation program in the cardiology department and attending cardiology clinics at NHSL. They had followed the same pre-operative process. Convenience sampling was used and each post-CABG patient was matched with the preCABG counterpart for age, gender and body mass index (BMI). Patients who underwent any cardiac, thoracic, aortic or vascular procedures other than CABG were not included in the study. Informed written consent was obtained from the participants. Ethics clearance was obtained from the Ethics Review Committee of the Faculty of Medicine, University of Colombo. All patients had their standard anthropometric measurements [weight, height and body mass index (BMI)] obtained.

The study tool was the interviewer administered Ferrans and Powers Quality of Life Index - Cardiac IV Version, which has been used successfully in a number of treatment evaluations, including cardiac transplantations, heart and lung transplantations, cardiovascular disease, stroke and CABG. ${ }^{14}$ It measures satisfaction with different aspects of life as well as importance of each of these aspects to the individual. Both satisfaction and the importance sections contain 35 items which the respondents had to rate on a 6-point scale ranging from 1 (very dissatisfied/unimportant) to 6 (very satisfied/important) and from the following subscales; health and functioning, social and economic, psychological/spiritual, and family. The range of scores for each subscale is 0-30. Scores are calculated by weighting each satisfaction response with its paired importance response, summing the response, and dividing by the number of items answered. As the Ferrans and Powers Quality of Life Index - Cardiac
IV Version has not been culturally adapted and validated for Sri Lanka, the questionnaire written originally in English, was translated into Sinhalese and Tamil, back translated and pre-tested. QoL scores were calculated according to the Ferrans and Powers guidelines. Statistical analyses were performed with SPSS version 17.0.

\section{Results}

\section{Sample characteristics}

The pre-CABG and post-CABG groups each consisted of 50 participants (male: female 30:20 in each). Means of parameters in the pre-CABG and post-CABG groups were compared using independent sample $T$ test. As there were no significant differences in means $(p>0.05)$ of age, weight, height and BMI, between the two groups, (Table 1), the pre-CABG and post-CABG groups can be considered homogenous.

\section{Quality of life in the pre-CABG and post-CABG groups}

Mean scores for health and functioning, social and economic, psychological/spiritual and family subscales of QoL and overall QoL in pre-CABG and post-CABG groups are shown in Table 2.

The post-CABG group had higher mean scores than the pre-CABG group for overall QoL and all subscales of QoL except the social and economic subscale, which had the lowest score in the post-CABG group. The highest scores in both groups was in the family subscale. The health and functioning subscale, which had the lowest score in the pre-CABG group, had the second highest scores in the post-CABG group.

\section{Variation of quality of life with gender in pre-CABG and post-CABG groups}

Mean scores for health and functioning, social and economic, psychological/spiritual and family subscales of QoL and overall QoL were compared between men and women in each of pre-CABG and post-CABG groups using independent sample $T$ test. There was no significant difference ( $p>0.05)$ in QoL scores between men and women in either group (Table 3).

\section{Variation of quality of life with age in pre-CABG and post-CABG groups}

Mean scores for health and functioning, social and economic, psychological/spiritual and family subscales of QoL and overall QoL of elder (age $\geq 60$ years) and younger (age $<60$ years) patients were compared in each of pre-CABG and post-CABG groups using independent sample $T$ test. There was no significant difference $(p>0.05)$ in QoL scores between men and women in each of the two groups except in the health and functioning subscale $(p<0.05)$ of the post-CABG group, for which the older group had higher scores (Table 4). 
Table 1. Comparison of sample characteristics between pre-CABG and post-CABG groups

\begin{tabular}{lllllll}
\hline & & $n$ & Mean & SD & $T$ value & $P$ value \\
\hline Age (years) & Pre-CABG & 50 & 57.24 & 6.22 & & \\
& Post-CABG & 50 & 57.4 & 6.22 & 0 & 1 \\
Height $(\mathrm{m})$ & Pre-CABG & 50 & 1.59 & 0.09 & & \\
& Post-CABG & 50 & 1.61 & 0.08 & -1.227 & 0.223 \\
Weight $(\mathrm{kg})$ & Pre-CABG & 50 & 66.76 & 9.68 & & \\
& Post-CABG & 50 & 67.92 & 8.49 & -0.637 & 0.526 \\
BMI $(\mathrm{kg} / \mathrm{m})^{2}$ & Pre-CABG & 50 & 26.44 & 2.76 & & \\
& Post-CABG & 50 & 26.50 & 2.62 & -0.116 & 0.908 \\
\hline
\end{tabular}

BMI-body mass index, CABG-Coronary artery bypass grafting, SD-Standard deviation

Table 2. Descriptive analysis of $Q \circ L$ in pre-CABG and post-CABG groups

\begin{tabular}{lcccc}
\hline Subscale of QLI & $n$ & $\begin{array}{c}\text { Pre-CABG group } \\
\text { Mean score (+/-SD) }\end{array}$ & $n$ & $\begin{array}{c}\text { Post-CABG group } \\
\text { Mean score (+/-SD) }\end{array}$ \\
\hline Health and functioning & 50 & $16.64(1.20)$ & 50 & $24.55(1.15)$ \\
Social and economic & 50 & $22.02(1.97)$ & 50 & $20.03(1.93)$ \\
Psychological/spiritual & 50 & $20.03(1.93)$ & 50 & $24.39(1.04)$ \\
Family & 50 & $23.74(1.77)$ & 50 & $25.52(1.95)$ \\
Overall QoL & 50 & $19.51(0.90)$ & 50 & $24.24(0.71)$ \\
\hline
\end{tabular}

CABG-Coronary artery bypass grafting, QLI-Quality of life index, QoL-Quality of life, SD-Standard deviation

Table 3. Variation of $Q \circ L$ scores with gender in pre-CABG and post-CABG groups

\begin{tabular}{lllcccccc}
\hline & \multicolumn{9}{c}{$\begin{array}{c}\text { Pre-CABG group } \\
\text { Subscale of QLI }\end{array}$} & Gender & $n$ & $\begin{array}{c}\text { Mean score } \\
(+/-S D)\end{array}$ & $\begin{array}{c}T \\
\text { value }\end{array}$ & $\begin{array}{c}P \\
\text { value }\end{array}$ & $\begin{array}{c}\text { Mean score } \\
(+/-S D)\end{array}$ & $\begin{array}{c}T \\
\text { value }\end{array}$ & $\begin{array}{c}P \\
\text { value }\end{array}$ \\
\hline Health and & Male & 30 & $16.56(1.28)$ & & & $24.49(1.12)$ & & \\
functioning & Female & 20 & $16.76(1.09)$ & -0.583 & 0.563 & $24.65(1.22)$ & -0.477 & 0.636 \\
Social and & Male & 30 & $21.80(2.01)$ & & & $22.48(1.99)$ & & \\
economic & Female & 20 & $22.34(1.91)$ & -0.943 & 0.350 & $22.66(1.47)$ & -0.345 & 0.732 \\
Psychological/ & Male & 30 & $20.07(2.21)$ & & & $24.25(1.05)$ & & \\
spiritual & Female & 20 & $19.98(1.48)$ & 0.161 & 0.873 & $24.59(1.02)$ & -1.153 & 0.255 \\
Family & Male & 30 & $23.70(1.84)$ & & & $25.80(2.05)$ & & \\
& Female & 20 & $23.79(1.70)$ & -0.181 & 0.857 & $25.10(1.75)$ & 1.248 & 0.218 \\
Overall QoL & Male & 30 & $19.44(0.97)$ & & & $24.21(0.75)$ & & \\
& Female & 20 & $19.60(0.79)$ & -0.628 & 0.533 & $24.29(0.67)$ & -0.361 & 0.720 \\
\hline
\end{tabular}

CABG - Coronary artery bypass grafting, QLI-Quality of life index, QoL-Quality of life, SD-Standard deviation 
Table 4. Variation of QoL scores with age in pre-CABG and post-CABG groups

\begin{tabular}{|c|c|c|c|c|c|c|c|c|}
\hline \multirow[b]{2}{*}{ Subscale of QLI } & \multirow[b]{2}{*}{$\begin{array}{l}\text { Age } \\
\text { group }\end{array}$} & \multirow[b]{2}{*}{$n$} & \multicolumn{3}{|c|}{ Pre-CABG group } & \multicolumn{3}{|c|}{ Post-CABG group } \\
\hline & & & $\begin{array}{c}\text { Mean score } \\
(+/-S D)\end{array}$ & $\begin{array}{c}T \\
\text { value }\end{array}$ & $\begin{array}{c}P \\
\text { value }\end{array}$ & $\begin{array}{c}\text { Mean score } \\
(+/-S D)\end{array}$ & $\begin{array}{c}T \\
\text { value }\end{array}$ & $\begin{array}{c}P \\
\text { value }\end{array}$ \\
\hline \multirow{2}{*}{$\begin{array}{l}\text { Health and } \\
\text { functioning }\end{array}$} & Elder & 15 & $16.84(1.32)$ & & & $25.05(0.55)$ & & \\
\hline & Younger & 35 & $16.56(1.15)$ & 0.750 & 0.457 & $24.34(1.28)$ & 2.052 & 0.000 \\
\hline \multirow{2}{*}{$\begin{array}{l}\text { Social and } \\
\text { economic }\end{array}$} & Elder & 15 & 22.19 (1.99) & & & 22.75 (1.97) & & \\
\hline & Younger & 35 & 21.94 (1.99) & 0.402 & 0.689 & $22.46(1.73)$ & 0.521 & 0.605 \\
\hline \multirow{2}{*}{$\begin{array}{l}\text { Psychological/ } \\
\text { spiritual }\end{array}$} & Elder & 15 & $19.54(1.81)$ & & & $24.54(0.82)$ & & \\
\hline & Younger & 35 & $20.24(1.97)$ & -1.179 & 0.244 & $24.32(1.13)$ & 0.694 & 0.491 \\
\hline \multirow[t]{2}{*}{ Family } & Elder & 15 & $23.53(1.50)$ & & & 25.61 (1.94) & & \\
\hline & Younger & 35 & $23.83(1.88)$ & -0.530 & 0.599 & 25.48 (1.98) & 0.212 & 0.833 \\
\hline \multirow[t]{2}{*}{ Overall QoL } & Elder & 15 & $19.54(0.91)$ & & & $24.54(0.64)$ & & \\
\hline & Younger & 35 & $19.49(0.91)$ & 0.160 & 0.874 & $24.11(0.72)$ & 1.997 & 0.052 \\
\hline
\end{tabular}

CABG-Coronary artery bypass grafting, QLI-Quality of life index, QoL-Quality of life, SD-Standard deviation

\section{Discussion}

\section{Pre and post-operative QoL}

The ACC/AHA guidelines for CABG suggest that improvement in QoL is a primary indication of CABG. ${ }^{13}$ This study revealed that the QoL was higher in both men and women after CABG, which is supported by published literature. ${ }^{16-21,22-29}$ It was interesting to note that higher scores were seen in all domains of QoL in the post-CABG group, except the socio-economic domain. These differences may be attributed to multiple factors, eg. the direct benefits of revascularization with enhanced cardiovascular function due to CABG, or factors indirectly linked to the surgery and ischaemic heart disease such as post-operative rehabilitation program, dietary changes, smoking cessation and psychological benefits. However, this was only a descriptive study which was not aimed at identifying what caused the improvement in QOL post-CABG. The lower scores obtained for the socioeconomic domain in the post-CABG group may be due to multiple reasons: though the CABG was carried out in the state sector, the expenses incurred during and after surgery may be higher than what was anticipated, the ability for income generation may have not improved as expected despite better physical well-being, inability to regain the financial losses during the period of illness and recovery and inadequate time for expected improvements in socio-economic status following CABG, as the post-CABG patients were recruited within only 10-15 months after surgery.

\section{QoL variations with gender}

The results of this study indicate that there are no significant gender differences in QoL either before or after CABG. Our findings are consistent with other studies ${ }^{27,29}$ which show similar improvements in QoL in both genders after CABG, whereas somer studies ${ }^{16,18,20,22}$ have found a poorer recovery in terms of QoL in women. The nonsignificance of gender difference in the present study may be due to the small sample size. However, the explanatory power and validity of studies might be limited by either small sizes and/or different time frames. And also after surgery, the traditional role demands may be particularly stressful for women and may thus enhance the disparities in QoL.

\section{QoL variations with age}

In our study, QoL in post-CABG group was better than that in the pre-CABG group regardless of age. According to United Nations age of 60 years was used as the cut-off to define the elder population in this study ${ }^{15}$. We found that pre-CABG QoL scores were similar and QoL was better than the pre-CABG group in the postCABG group in both older and younger patients. In fact, older patients showed both higher scores and also greater differences in scores in all the subscales as well as the overall QoL scores. These findings suggest that older patients can expect similar differences in QoL postoperatively as their younger counterparts, which is also reported in other studies..$^{17,18,22}$ As seen in other studies ${ }^{18,22}$ our findings demonstrated that, there was a remarkable difference in QoL in health and functioning domain in >60 years group compared with their $<60$ years group. This subscale dealing with general health, symptoms and activities of daily living is thought to be significantly better in the elders after CABG. It is also interesting to note the higher QoL scores in the post-CABG group among the older patients, compared to the younger ones in all subscales as well as the overall score, which was not seen in the pre-CABG group. A possible explanation for this finding is that younger patients face different 
challenges in their post-operative lives with higher expectations at home and work which they may not have been able to fulfill, leading to lower reported QoL.

There are several limitations identified in this study. The sample size is small and it was difficult to match preoperative subjects with post-operative subjects on age, gender and BMI, as two separate groups were studied before and after $\mathrm{CABG}$, rather than following up the same cohort and evaluating the differences in QoL between pre-CABG and post-CABG groups. It is also possible that there is a selection bias in the post-CABG group, as the post-CABG patients attending the rehabilitation program in the cardiology department and attending cardiology clinics at NHSL are a motivated group who may therefore have a better outcome and QoL. Pre and post-CABG QoL may be influenced by factors such as non-cardiac problems and pre-operative, peri-operative and post-operative surgical complications which were not evaluated.

\section{Conclusion}

This study focused on the evaluation of the QoL of two groups of patients before and after CABG. In the postCABG group, the QoL associated with health and functioning, psychological and spiritual activities and family life as well as overall QoL appear to be better than in the pre-CABG group, though their QoL linked to social and economic activities seem worse than in the preCABG group. The higher scores for QoL in the postCABG group were reported, regardless of age and gender. However, in the post-CABG group, the elders report significantly better QoL related to health and functioning compared to their younger counterparts. Conducting the study at the NHSL, a major center for the cardiac surgeries in Sri Lanka, enhances the generalizability of the results of this study. Larger studies using a more representative sample, following up the same cohort in prospective studies which also consider co-morbidities would be useful in strengthening the above findings.

\section{Declaration}

This paper has been presented as an oral presentation at the Second International Conference on Global Public Health 2014, Negombo, Sri Lanka July, 2014. Published in proceedings - OP1, pp11.

\section{References}

1. Alwan $A(e d)$. Global status report on non communicable diseases 2010. World Health Organization. 2011.

2. Mendis S, Puska P, Norrving B (eds). Global atlas on cardiovascular disease prevention and control. World Health Organization. 2011.

3. Thomas A, Gaziano TA, Bitton A, Murphy A. Growing
Epidemic of Coronary Heart Disease in Low- and MiddleIncome Countries. Current Problems in Cardiology 2010; 35(2): 72-115.

4. Annual Health Bulletin Srilanka -2003, Ministry of HealthSri Lanka.

5. Abeywardena MY. Dietary fats, carbohydrates and vascular disease: Sri Lankan perspectives. Atherosclerosis 2003; 171(2): 157-61.

6. Fernando R. A study of the investigation of death (coroner system) in Sri Lanka. Medicine, Science and the Law 2003; 43(3): 236-40.

7. Roger VL et al. Heart Disease and Stroke Statistics - 2011 Update. A Report from the American Heart Association. Circulation 2011; 123: e18-e209.

8. Hillis LD, Smith PK, Anderson JL, et al. 2011 ACCF/AHA Guideline for Coronary Artery Bypass Graft Surgery: a report of the American College of Cardiology Foundation/ American Heart Association Task Force on practice Guidelines. Circulation 2011; 124(23): e652-735.

9. ElBardissi AW, Aranki SF, Sheng S, O'Brien SM, Greenberg CC, Gammie JS. Trends in isolated coronary artery bypass grafting: an analysis of the Society of Thoracic Surgeons adult cardiac surgery database. The Journal of Thoracic and Cardiovascular Surgery 2012; 143(2): 273-81.

10. Cardio thoracic Surgeries. The National Hospital of Sri Lanka.http://www. nationalhospital.Ik/vservices. php?link=CARDIO-THORACIC\%20SURGERY.

11. Rumsfeld JS, Magid DJ, Brien MO, McCarthy M, Whinney SM, Shroyer ALW, Moritz TE, Henderson WG, Sethi GK, Grover FL, Hammermeister KE. Changes in Health Related Quality of Life Following Coronary Artery Bypass Graft Surgery. The Annals of Thoracic Surgery. 2001; 72 (6): 2026-32.

12. Grady KL, Lee R, Subacius H, Malaisri SC. Improvements in Health-Related Quality of Life Before and After Isolated Cardiac Operations. The Annals of Thoracic Surgery. 2011; 91(3): 777-83.

13. Hillis LD et al. 2011 ACCF/AHA Guideline for Coronary Artery Bypass Graft Surgery: A Report of the American College of Cardiology Foundation/ American Heart Association Task Force on Practice Guidelines. Circulation 2011; 124: e574-e651.

14. Ferrans CE, Powers MJ. Quality of Life Index: development and psychometric properties. Advances in Nursing Science1985; 8(1): 15-24.

15. World Health Organization. Definition of an older or elderly person. 2013. Available from: http://www.who.int/healthinfo /survey/ageingdefnolder/en.

16. Keresztes AP, Merritt SL, Holm K, Penckofer S, Patel M. The coronary artery bypass experience: gender differences. Heart and Lung 2003; 32(5): 308-19.

17. Kurfirst $\vee$ et al. Health-related quality of life after cardiac surgery - the effects of age, preoperative conditions and postoperative complications. Journal of Cardiothoracic Surgery 2014; 9: 46.

18. Koch CG, Khandwala F, Cywinski JB, Ishwaran H, Estafanous FG, Loop FD, Blackstone EH. Health-related quality of life after coronary artery bypass grafting: A 
gender analysis using Duke Activity Status. The Journal of Thoracic and Cardiovascular Surgery 2004; 128(2): 284-95.

19. Dunning J, Waller JRL, Smith J, Pitts S, Kendall SWH, Khan K. Coronary Artery Bypass Grafting is Associated With Excellent Long-Term Survival and Quality of Life: A Prospective Cohort Study. The Annals of Thoracic Surgeries 2008; 85(6): 1988-93.

20. Kendel F, Dunkel A, Tasch TM, Steinberg K, Lehmkuhl E, Hetzer R, Zagrosek VR. Gender Differences in HealthRelated Quality of Life After Coronary Bypass Surgery: Results From a 1-Year Follow-Up in Propensity-Matched Men and Women. Psychosomatic Medicine 2011; 73: 217.

21. Grady KL, Lee R, Subacius H, Malaisri SC. Improvements in Health-Related Quality of Life Before and After Isolated Cardiac Operations. The Annals of Thoracic Surgery 2011; 91(3): 777-83.

22. Simchen E, Galai N, Braun D, Gurevich YZ, Shabtai E, Naveh I. Sociodemographic and clinical factors associated with low quality of life one year after coronary bypass operations: The Israeli Coronary Artery Bypass Study (ISCAB). The Journal of Thoracic and Cardiovascular Surgery 2001; 121(5): 909-19.

23. Noyez L, Schultz A, van der Heide SM, van Eck FM, Brouwer RMHJ. Evaluation of long-term quality of life after reoperative coronary artery surgery: preliminary results. Netherlands Heart Journal. 2003; 11(12): 500-5.
24. Merkouris A, Apostolakis E, Pistolas D, Papagiannaki V, Diakomopoulou E, Patiraki E. Quality of life after coronary artery bypass graft surgery in the elderly. European Journal of Cardiovascular Nursing 2008; 8(1): 74-81.

25. Hunt JO, Hendrata MV, Myles PS. Quality of life 12 months after coronary artery bypass graft surgery. Heart and Lung 2000; 29(6): 401-11.

26. Baldassarre FG, Arthur HM, DiCenso A, Guyatt G. Effect of coronary artery bypass graft surgery on older women's health-related quality of life. Heart and Lung. 2002; 31 (6): 421-31.

27. Lindquist R, Dupuis G, Terrin ML, Hoogwerf B, Czajkowski $S$, Herd JA, Barton FB, Tracy MF, Hunninghake DB, Jacobson DT, Shumaker S, Zyzanski S, Goldenberg I, Knatterud GL. Comparison of Health-Related Quality-ofLife Outcomes of Men and Women After Coronary Artery Bypass Surgery Through 1 Year: Findings From The POST CABG Biobehavioral Study. American Heart Journal 2003; 146(6): 1038-44.

28. Höfer S, Doering S, Rumpold G, Oldridge N, Benzer W. Determinants of health-related quality of life in patients with coronary artery disease. European Journal of Cardiovascular Prevention and Rehabilitation 2006; 13: 398-406.

29. Bradshaw PJ, Jamrozik KD, Gilfillan IS, Thompson PL. Asymptomatic long-term survivors of coronary artery bypass surgery enjoy a quality of life equal to the general population. American Heart Journal 2006; 151(2): 537-44. 